\title{
Design of Single Gold Atoms on Nitrogen-Doped Carbon for Molecular Recognition in Alkyne Semi-Hydrogenation
}

\author{
Ronghe Lin ${ }^{+}$, Davide Albani , Edvin Fako, Selina K. Kaiser, Olga V. Safonova, Núria López,* \\ and Javier Pérez-Ramírez*
}

\begin{abstract}
Single-atom heterogeneous catalysts with welldefined architectures are promising for deriving structureperformance relationships, but the challenge lies in finely tuning the structural and electronic properties of the metal. To tackle this point, a new approach based on the surface diffusion of gold atoms on different cavities of $\mathrm{N}$-doped carbon is presented. By controlling the activation temperature, the coordination neighbors $(\mathrm{Cl}, \mathrm{O}, \mathrm{N})$ and the oxidation state of the metal can be tailored. Semi-hydrogenation of various alkynes on the single-atom gold catalysts displays substratedependent catalytic responses; structure insensitive for alkynols with $\gamma$-OH and unfunctionalized alkynes, and sensitive for alkynols with $\alpha-O H$. Density functional theory links the sensitivity for alkynols to the strong interaction between the substrate and specific gold-cavity ensembles, mimicking a molecular recognition pattern that allows to identify the cavity site and to enhance the catalytic activity.
\end{abstract}

\section{I} dentifying the structure of the active site of a catalyst is pivotal for rational design. While the architecture of homogeneous systems can be easily characterized, the analogue in heterogeneous catalysis remains very challenging due to the inherent material complexity, even though advanced in situ and operando techniques are nowadays widely available. For this reason, synthesis of heterogeneous metal catalysts with well-defined active ensembles to mimic organometallic complexes is regarded as an elegant approach, which might not only enable selective transformations, ${ }^{[1]}$ but exquisitely lead to the establishment of new structure-performance relation-

[*] Dr. R. Lin,,$^{[+]}$D. Albani, ${ }^{[+]}$S. K. Kaiser, Prof. J. Pérez-Ramírez Institute for Chemical and Bioengineering

Department of Chemistry and Applied Biosciences ETH Zurich

Vladimir-Prelog-Weg 1, 8093 Zurich (Switzerland)

E-mail: jpr@chem.ethz.ch

E. Fako, Prof. N. López

Institute of Chemical Research of Catalonia (ICIQ)

The Barcelona Institute of Science and Technology

Av. Països Catalans 16, 43007 Tarragona (Spain)

E-mail:nlopez@iciq.es

Dr. O. V. Safonova

Paul Scherrer Institute

5232 Villigen PSI (Switzerland)

$\left.{ }^{+}\right]$These authors contributed equally to this work.

(6) Supporting information (catalyst preparation, characterization, and

evaluation as well as computational methods) and the ORCID

identification number(s) for the author(s) of this article can be found under:

https://doi.org/10.1002/anie.201805820. ships. ${ }^{[2]}$ Single-atom heterogeneous catalysts (SAHCs), a class of burgeoning materials with diverse applications in chemical transformation ${ }^{[2 a, c]}$ and energy conversion, ${ }^{[3]}$ can be envisaged as the missing link between homogeneous and heterogeneous systems owing to the intrinsic cationic nature and well isolation of the single metal atoms entrapped in a solid material acting as ligand. To overcome their tendency of metal agglomeration, extensive efforts have been devoted to developing effective synthetic strategies via either introducing suitable anchoring sites or creating strong metal-support interactions, as recently well documented for a wide range of transition metals on different hosts. ${ }^{[4]}$ Despite being successfully applied in different reactions, still the rational design of SAHCs for targeted applications is at the initial stage. Consequently, this leads to a knowledge gap whether concepts belonging to homogeneous catalysts could be transposed to the heterogeneous counterparts.

Catalysis by gold has witnessed exceptional growth in diverse fields since this metal is both effective as a homogeneous or a heterogeneous catalyst. ${ }^{[5]}$ In view of the nowadays growing importance of gold nanoparticles and single atoms in hydrogenation, ${ }^{[6]}$ oxidation, ${ }^{[7]}$ water-gas shift, ${ }^{[2 a, b]}$ and hydrochlorination, ${ }^{[8]}$ an in depth study on the precise control over the metal oxidation state and coordination sphere of single gold atoms using nitrogen-doped carbon (NC) is targeted. This is achieved by inducing surface diffusion of metal atoms on the diverse anchoring sites of the host, which leads to the creation of a series of single-atom gold ensembles with welldefined structures and electronic properties. Inspired by the opposite origins for supported gold nanoparticles and homogeneous gold complexes governing the selective activation of alkynes (a phenomenon known as alkynophilicity ${ }^{[9]}$ ), the $\mathrm{Au}$ SAHCs with precise architectures are assessed in the semihydrogenation of alkynes to establish catalyst design rules.

Gold was deposited via incipient wetness impregnation of $\mathrm{HAuCl}_{4}$ in an aqua regia solution either on sulfur-free polyaniline-derived high $\mathrm{N}$-content $\mathrm{NC}$ (ca. $10 \mathrm{wt} \%)^{[10]}$ or activated carbon (AC, as a reference) followed by thermal activation at different atmospheres and temperatures (413$1073 \mathrm{~K}$ ) for $16 \mathrm{~h}$ (Figure 1, see the Supporting Information for more details). The temperature-dependent evolution of $\mathrm{Au}$ particle size for both series was followed by X-ray diffraction patterns (XRD). Apart from showing the amorphous nature of the NC support and the absence of any Au related diffraction patterns on $\mathrm{Au} / \mathrm{NC}-T$ (where $T$ stands for the treatment temperature applied), it reveals the characteristic peaks of the $\mathrm{Au}(111)$ facet at $T \geq 573 \mathrm{~K}$ on the AC reference (Figure S1). The diverging evolution of the gold atoms on both carriers was further analyzed by combining high-angle 


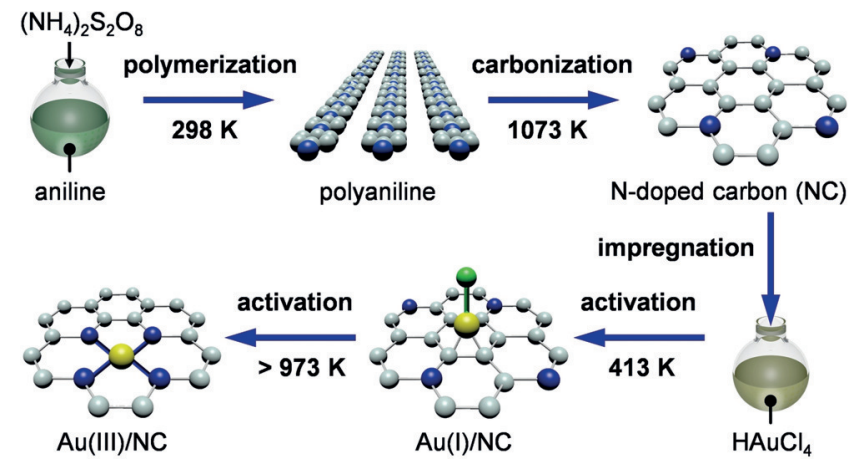

Figure 1. Synthetic steps involved in the preparation of nitrogen-doped carbon (NC) with a high density of electron-rich cavities: oxidative polymerization of aniline with ammonium persulfate to polyaniline and subsequent carbonization of the polymer at $1073 \mathrm{~K}$, and the subsequent preparation of supported single-atom gold catalysts via incipient wetness impregnation of $\mathrm{NC}$ with $\mathrm{HAuCl}_{4}$ in aqua regia solution, followed by thermal activation step in static air $(\leq 473 \mathrm{~K})$ or flowing $\mathrm{N}_{2}$ $(>473 \mathrm{~K}$ ) for $16 \mathrm{~h}$. Au yellow, $\mathrm{C}$ gray, $\mathrm{N}$ blue, and $\mathrm{Cl}$ green.

annular dark-field scanning transmission electron microscope (HAADF-STEM, Figure $2 \mathrm{a}, \mathrm{b}$, Figures S2 and S3 in the Supporting Information) and extended X-ray absorption fine structure spectroscopy (EXAFS, Figure 2e), confirming that the gold species are present as single atoms on the NC carrier even up to $1073 \mathrm{~K}$. In stark contrast, single $\mathrm{Au}$ atoms hosted on the $\mathrm{AC}$ are stable only at $413 \mathrm{~K}$ and dramatic agglomeration occurs readily at $T \geq 573 \mathrm{~K}$, featuring scattering peaks assigned to the $\mathrm{Au}-\mathrm{Au}$ bonds in the $\mathrm{Au} / \mathrm{AC}-673$ sample (Figure 2e) and very wide particle size distribution (Figure S4)

To assess the individual roles of aqua regia and the $\mathrm{N}$ sites, an additional $\mathrm{Au} / \mathrm{NC}-413\left(\mathrm{H}_{2} \mathrm{O}\right)$ sample was prepared using deionized water as solvent. The XRD patterns of the sample dried at $413 \mathrm{~K}$ show clear reflections of metallic gold (Figure S1). This result together with the diverging evolution of gold on both carbon hosts highlights the important roles of the solvent and $\mathrm{N}$ dopant in stabilizing single-gold atoms on the carbon host (details are given in the Supporting Information).

To reveal the nature of the gold species on $\mathrm{Au} / \mathrm{NC}-\mathrm{T}$ and $\mathrm{Au} / \mathrm{AC}-T$, X-ray photoelectron spectroscopy (XPS) was conducted. Interestingly, for the $\mathrm{NC}$ series the $\mathrm{Au} 4 \mathrm{f}$ core level spectra steadily shift to higher binding energy (BE) upon increasing activation temperature (Figure $2 \mathrm{c}$ ). This behavior is not observed on the $\mathrm{AC}$ references, as evidenced from the similar $\mathrm{Au} 4 \mathrm{f}_{7 / 2}$ peaks at $\mathrm{BE}=84.2 \mathrm{eV}$ for metallic $\mathrm{Au}$ on both $\mathrm{Au} / \mathrm{AC}-413$ and $\mathrm{Au} / \mathrm{AC}-673$. Detailed XPS fitting for $\mathrm{Au} / \mathrm{NC}$ samples indicates that the low-temperature sample contains predominantly $\mathrm{Au}$ species at $\mathrm{BE}=84.2 \mathrm{eV}$ which decrease in population with increasing temperature, while the contents of $\mathrm{Au}^{+}(\mathrm{BE}=85.0 \mathrm{eV})$ and $\mathrm{Au}^{3+}(\mathrm{BE}=87.0 \mathrm{eV})$ increase. At $T=1073 \mathrm{~K}, \mathrm{Au}^{3+}$ was the only species stable at such a high temperature. Thus, the well-behaved temperature dependency of the Au oxidation state enables ad hoc tuning of the $\mathrm{Au} / \mathrm{NC}$ system for targeted applications.

The precise assignment of the low BE peak should be done with caution as gold chloride species are highly light- sensitive and can be reduced to $\mathrm{Au}^{0}$ during XPS measurement. ${ }^{[1]}$ To complement the XPS findings, X-ray absorption near edge spectroscopy (XANES) was applied as a nondestructive technique for these sensitive materials. Figure $2 \mathrm{~d}$ presents the XANES spectra of relevant samples together with reference gold standards. For the two extreme $\mathrm{Au} / \mathrm{NC}$ samples (Au/NC-413 and $\mathrm{Au} / \mathrm{NC}-1073)$ and $\mathrm{Au} / \mathrm{AC}-413$, a clear white line peaked at approximately 11919-11920 eV was observed. Besides, the absorption threshold of gold, obtained from the first derivative of the normalized absorption curves (Figure S5), shows a clear shift to higher energy for the $\mathrm{Au} / \mathrm{NC}$ samples as compared to the $\mathrm{Au}$ foil, indicating the cationic gold speciation in these materials. ${ }^{[12]}$ On the contrary, the Au/AC-673, containing mainly Au nanoparticles, did not show these features, albeit sharing a similar Au 4f XPS spectrum. Still, differences between $\mathrm{Au} / \mathrm{NC}-413$ and $\mathrm{Au} / \mathrm{NC}-$ 1073 can be distinguished in their normalized white line intensity ( 0.73 vs. 1.15$)$, a feature corresponding to d-electron occupancy ${ }^{[8]}$ By comparing these values with those of gold references, we can thus confirm that $\mathrm{Au}^{+}$and $\mathrm{Au}^{3+}$ are the major species in $\mathrm{Au} / \mathrm{NC}-413$ and $\mathrm{Au} / \mathrm{NC}-1073$, respectively. The EXAFS analysis further reveals that $\mathrm{Au}$ was predominantly coordinated with $\mathrm{Cl}$ in $\mathrm{Au} / \mathrm{NC}-413$, and to $\mathrm{N}$ and/or $\mathrm{O}$ in $\mathrm{Au} / \mathrm{NC}-973$ and $\mathrm{Au} / \mathrm{NC}-1073$ (Figure 2e and Figure S6). The best fitting of the first shell reveals a coordination number $(\mathrm{CN})$ of 2.0 for $\mathrm{Cl}$, and 3.5 and 2.7, respectively, for $\mathrm{N} /$ $\mathrm{O}$ in the two high-temperature samples (Figure S6 and Table S4). This change in Au coordination atoms from $\mathrm{Cl}$ to $\mathrm{N} / \mathrm{O}$ upon high-temperature activation is fully supported by surface elemental concentrations determined by XPS, as the substantial amount of $\mathrm{Cl}$ in the low-temperature samples ( $\mathrm{Cl}: \mathrm{Au}>37$, molar ratio) was almost completely removed after treatment at $T \geq 973 \mathrm{~K}$, but the $\mathrm{N}$ content remains rather stable (Figure S7 and Table S3).

The remarkable stabilization of single $\mathrm{Au}$ atom on the NC carrier was rationalized by density functional theory (DFT). The most representative coordination environments were determined (Figure $2 \mathrm{f}$ ) by analyzing the intrinsic stability (Tables S6, S7 and Figure S8), the ability to bind $\mathrm{Au}$ or $\mathrm{AuCl}$, and the barriers for diffusion of gold species from the cavity to the host surface of several nitrogen defects. The analysis of formation energy $(E)$ of an isolated $\mathrm{AuCl}$ molecule on multiple cavities reveals that $\mathrm{NC}-\mathrm{Au}-\mathrm{Cl}$ moiety is thermodynamically stable on diverse structures. Since at low temperatures relatively high amounts of $\mathrm{Cl}$ are present, in $\mathrm{Au} / \mathrm{NC}$ 413 the photosensitive $\mathrm{NC}-\mathrm{Au}-\mathrm{Cl}$ species (from b1 to b6, Figure 2f) are likely displayed as $\mathrm{Au}^{0}(\mathbf{a 1}, E=-1.48 \mathrm{eV})$ by XPS analysis (vide supra). Upon increasing the temperature, the removal of $\mathrm{Cl}$ in combination with the higher mobility of $\mathrm{Au}$ atoms leads to the emergence of the $\mathrm{Au}^{+}$feature at $573 \mathrm{~K}$ corresponding to the oxidized-4-pyridinic structure (a4, $E=$ $-1.71 \mathrm{eV})$. The calculated $\mathrm{Au} 4 \mathrm{f}$ XPS shift is much higher than that experimentally observed $(1.74$ vs. $0.80 \mathrm{eV})$, indicating likely $\mathrm{Au}^{\delta+}(1<\delta<3)$ species in a4. A further temperature increase involves higher diffusion of gold species that enter the $\mathbf{a} 6$ cavity adopting a four-fold $\mathrm{N}$-coordinated planar geometry, which represents the global diffusion minima $(E=$ $-3.61 \mathrm{eV}$ ) and is observed as $\mathrm{Au}^{3+}$ by XPS and EXAFS. 


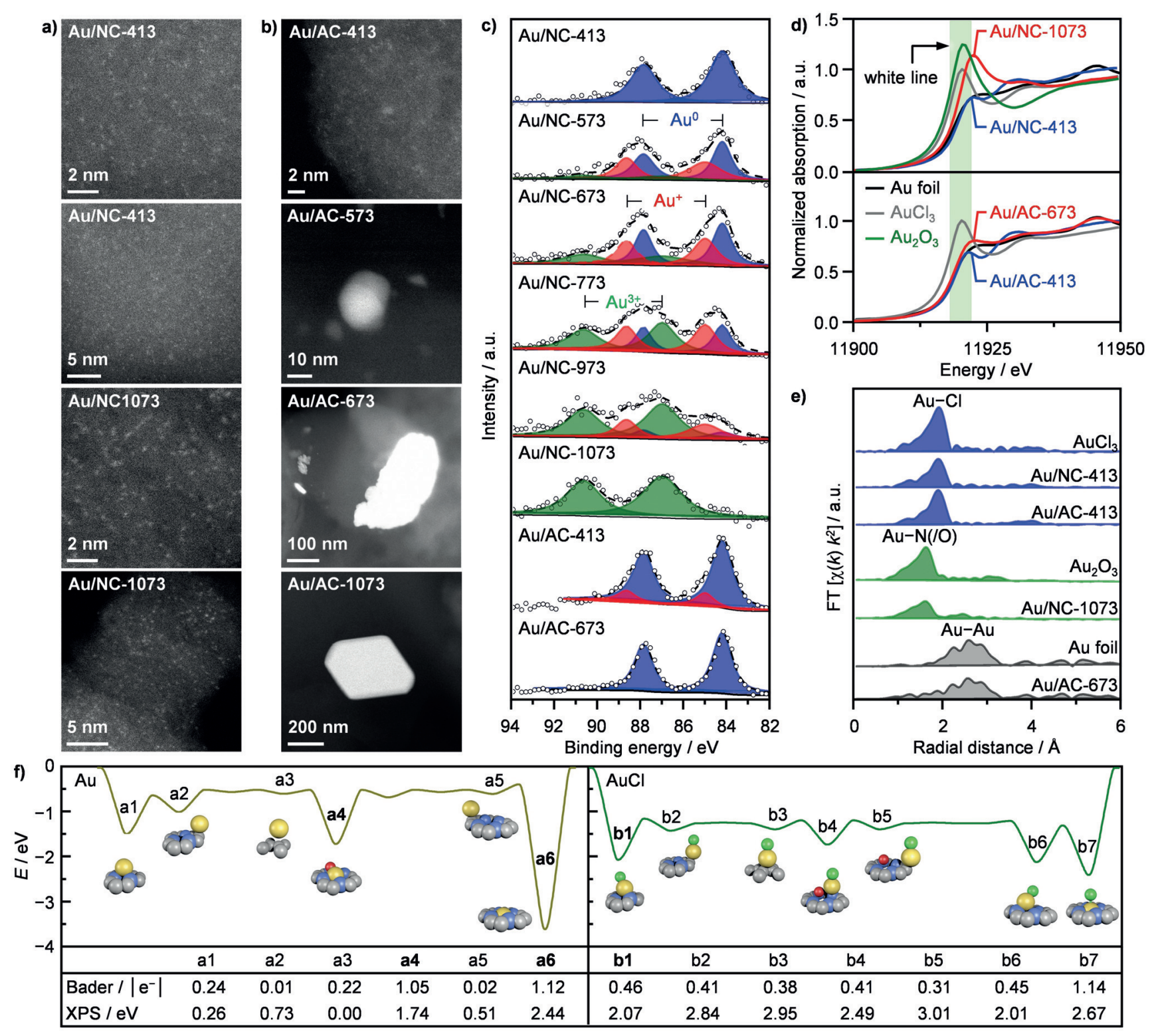

Figure 2. a) Aberration corrected HAADF-STEM micrographs of Au/NC-T and b) HAADF-STEM images of Au/AC-T catalysts, presenting the comparative evolution of gold atoms on the two carriers. c) Au $4 \mathrm{f}$ core level XPS spectra and, d) ex situ Au $L_{3}$ edge-normalized XANES spectra together with e) the FT-EXAFS spectra of key gold catalysts and reference samples. $f$ ) Energy profiles for the surface diffusion of $\mathrm{Au}$ and $\mathrm{AuCl}$ between 3-pyridinic, graphite, oxidized-4-pyridinic and 4-pyridinic, with the Bader charges and Au $4 \mathrm{fXPS}$ shifts (relative to an Au atom on the graphite basal plane, Au yellow, $\mathrm{C}$ gray, $\mathrm{N}$ blue, $\mathrm{O}$ red, $\mathrm{Cl}$ green) presented in the bottom panel. The most representative gold species are highlighted in bold.

The performance of the nanostructured gold catalysts $(\mathrm{Au} / \mathrm{NC}-\mathrm{T}$ and $\mathrm{Au} / \mathrm{AC}-T)$ was evaluated in the continuous flow three-phase semi-hydrogenation of 1-hexyne and 2methyl-3-butyn-2-ol (Figure 3 a and Figure S9), two relevant reactions in the production of $\alpha$-olefins and synthesis of intermediate for vitamins. ${ }^{[13]}$ The single-atom catalyst Au/AC413 shows approximately three-fold higher activity than the rest $\mathrm{Au} / \mathrm{AC}$ samples containing mainly $\mathrm{Au}$ nanoparticles. On the other hand, the two substrates display strikingly different catalytic responses on the $\mathrm{Au} / \mathrm{NC}-\mathrm{T}$ series. While the 1hexyne hydrogenation activity is independent on the activation temperature and consequent Au speciation, a volcanolike curve is observed in the case of 2-methyl-3-butyn-2-ol. In accordance with the literature reports, ${ }^{[14]}$ all these gold systems give essentially full selectivity to the aimed alkenes. In addition, HAADF-STEM examination on the two extreme $\mathrm{Au} / \mathrm{NC}-T$ catalysts confirmed that the atomic dispersion of gold remains unaltered after the hydrogenation performance (Figure S10).

To gain confidence on the above catalytic phenomenon on $\mathrm{Au} / \mathrm{NC}-\mathrm{T}$, we then extend the substrate scope (Figure $3 \mathrm{~b}$ and Figure S9). The experimental results show that irrespective of the chain length (1-dodecyne) and the position of the $\mathrm{C} \equiv \mathrm{C}$ bond (4-octyne), the hydrogenation of unfunctionalized substrates does not show any dependence on the gold coordination sphere and speciation. Consistently, all adsorp- 

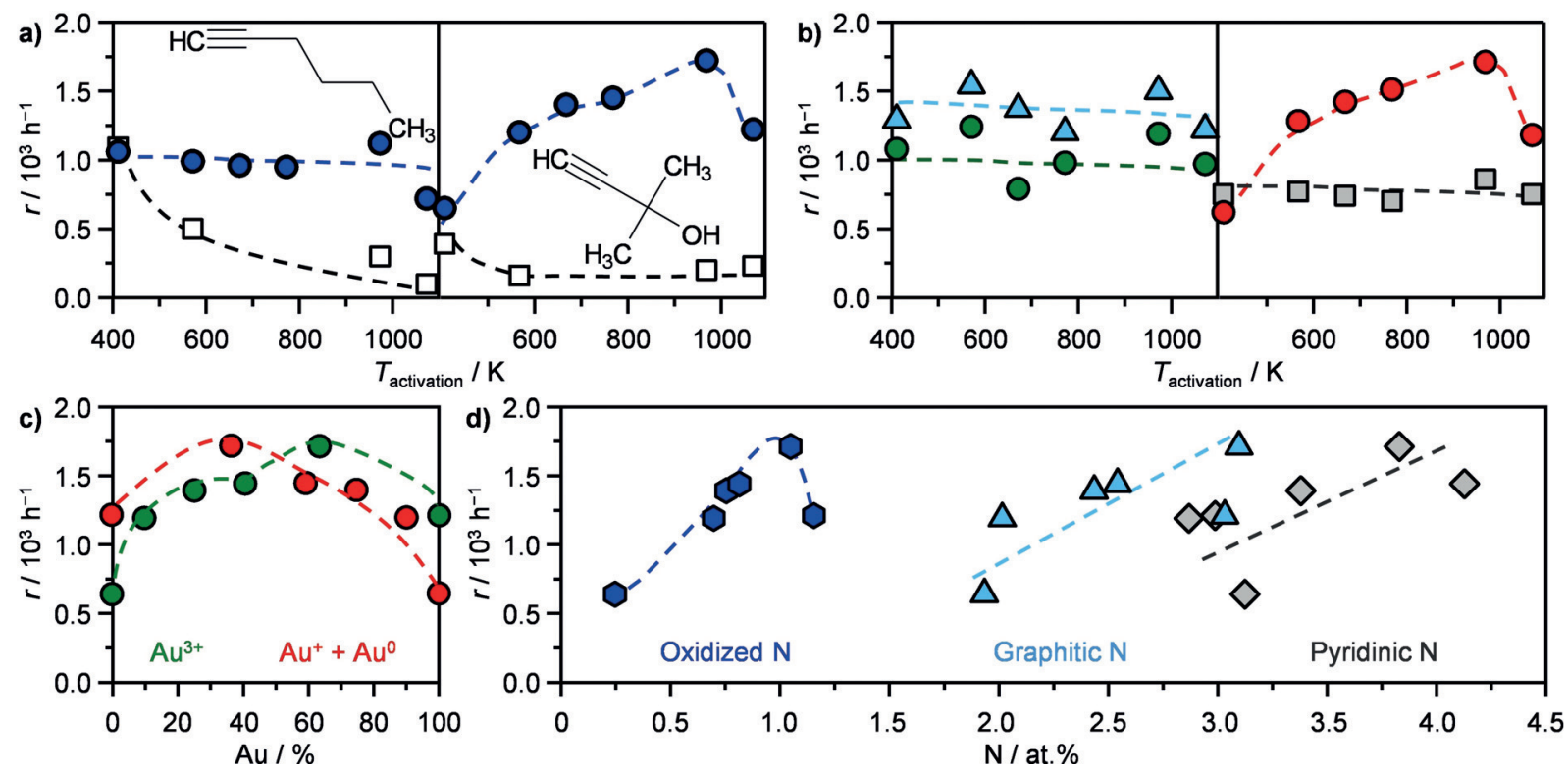

Figure 3. a) Comparative performance of Au/NC-T (circle) and Au/AC-T (square) catalysts in 1-hexyne and 2-methyl-3-butyn-2-ol semi-hydrogenation. b) Extrapolation of the substrate specificity to 1-dodecyne (light blue), 4-octyne (green), 3-methyl-1-pentyl-3-ol (red), and 4-pentyl-1ol (gray) over Au/NC-T. Reaction rate as a function of c) the Au oxidation state, based on the XPS fitting, and d) the nitrogen speciation. Conditions: $W_{\text {cat }}=0.1 \mathrm{~g}, T=303 \mathrm{~K}, P=3$ bar, $F_{\mathrm{L}}$ (alkyne + toluene) $=1 \mathrm{~cm}^{3} \mathrm{~min}^{-1}$, and $F_{\mathrm{G}}\left(\mathrm{H}_{2}\right)=48 \mathrm{~cm}^{3} \mathrm{~min}^{-1}$. The alkyne conversion levels are around $5-25 \%$ under typical reaction conditions on all the catalysts evaluated.

tion energies of acetylene and 1-hexyne on relevant $\mathrm{Au}$ species are within a narrow range (from -0.18 to $-0.53 \mathrm{eV}$; Figure $4 \mathrm{a}$ ), hinting that the molecules are bound in a similar manner. As evidenced in Figure S11, the slight difference in adsorption of the different substrates is due to the van der Waals contributions arising from the different numbers of the carbon atoms. Conversely, the reaction rate of 3-methyl-1pentyl-3-ol hydrogenation presents volcano behavior similar to 2-methyl-3-butyn-2-ol, while the $\gamma$-alcohol 4-pentyl-1-ol behaves like the other unfunctionalized alkynes showing structure insensitivity. Therefore, this molecular recognition pattern $^{[15]}$ can be employed to identify the nature of the active site in terms of $\mathrm{Au}$ oxidation state and cavity functionaliza- tion. From the reactant adsorption heatmaps we have identified that the most active site appearing at medium temperatures (773-973 K) is a4, which contains the oxidized4-pyridine cavity and the $\mathrm{Au}^{\delta+}$ species. Neither $\mathrm{Au}^{+}$nor $\mathrm{Au}^{3+}$ alone are activity descriptor for the hydrogenation, while (oxidized) pyridinic $\mathrm{N}$ shows good correlation (Figures $3 \mathrm{c}, \mathrm{d}$ ), supporting the above conclusion. The Au@a4 ensemble ensures that the adsorption of different alkynols (Figure $4 \mathrm{a}$ ) is maximal for the $\alpha$-ol due to the formation of a hydrogen bond, which is by far the largest adsorption obtained among all the alkynes studied (Figure S12). The reaction mechanism was then simulated on this specific site and consists of molecular hydrogen splitting by gold and the concomitant
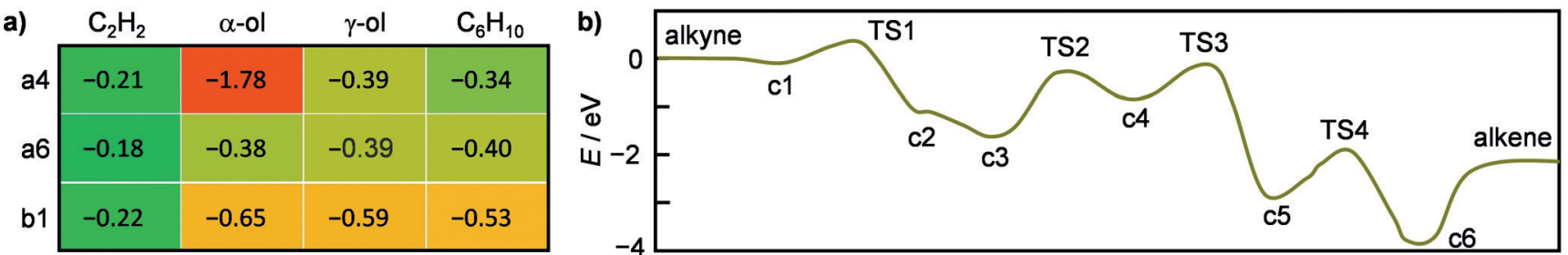

c)
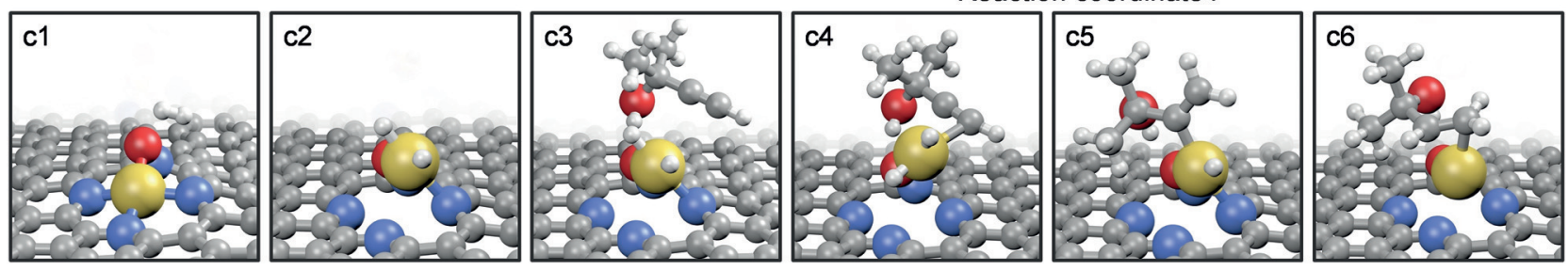

Figure 4. a) Heatmap for the adsorption of acetylene $\left(\mathrm{C}_{2} \mathrm{H}_{2}\right)$, 2-methyl-3-butyn-2-ol ( $\alpha$-alcohol, $\alpha$-ol), 4-pentyl-1-ol ( $\gamma$-alcohol, $\gamma$-ol) and 1-hexyne $\left(\mathrm{C}_{6} \mathrm{H}_{10}\right)$, and b) energy profile for the hydrogenation reaction of 2-methyl-3-butyn-2-ol on a single gold atom in the oxidized-4-pyridinic cavity. c) Side view of DFT-optimized adsorption configuration of the intermediates for the reaction profile in (b). 
adsorption of 2-methyl-3-butyn-2-ol to the metal center and the $\mathrm{N}-\mathrm{O}$ termination (Figure $4 \mathrm{~b}$ and Video $\mathrm{S} 1$ ). Then, the two activated $\mathrm{H}$ are sequentially added to the triple bond, forming the alkene that detaches from the material. To rationalize the higher activity of Au single atoms over the nanoparticle analogues, we have computed the full reaction profile of 2-methyl-3-butyn-2-ol on the $\mathrm{Au}(211)$ surface (Figure S13). By comparing the $\mathrm{H}_{2}$ activation step, the ratedetermining step for Au-based catalysts, ${ }^{[\mathrm{b}]}$ between Au@4 and $\mathrm{Au}(211)$, it is evidenced that the activation is significantly more thermodynamically favored on the single-atom sites than on the Au surface $(-1.13 \mathrm{eV}$ and $-0.17 \mathrm{eV}$, respectively). Thus, the population of activated $\mathrm{H}$ is much higher on the single-atom catalyst to further continue the reaction. Besides, the a4 site occupied by gold is also stable against hydrogen reduction (barrier $1.71 \mathrm{eV}$, Figure S14), that ensures the high stability of the hydrogenation performance as evidenced by HAADF-STEM of the used catalysts (see above).

In conclusion, we have developed an effective method to entrap single $\mathrm{Au}$ atoms with N-doped carbon, and demonstrated how to finely tailor their nature (oxidation state and coordination sphere) by taking advantage of their different thermal stability in the cavities of the host. Assessment of the diverse nanostructured gold catalysts in alkyne semi-hydrogenation confirms the higher activity of Au single atoms than nanoparticles. Furthermore, the hydrogenation over the single-atom $\mathrm{Au} / \mathrm{NC}-T$ catalysts shows structure insensitivity for unfunctionalized alkynes and alkynols with $\gamma$-OH respect to the triple bond, and structure sensitivity for alkynols with $\alpha-\mathrm{OH}$. Theoretical methods link this unprecedented sensitivity behavior to the strong interactions between the adsorbed alkynol molecules and the gold and oxidized-4-pyridinic $\mathrm{N}$ ensemble, resulting in specific molecular recognition pattern in alkyne semi-hydrogenation. Overall, the precise control of the anchoring sites of single metal atoms developed in this study represents a key step towards the rational catalyst design, providing a novel way for breaking linear scaling relations that can be extrapolated to other hydrogenations and beyond.

\section{Acknowledgements}

This work was supported by the Swiss National Science Foundation (project no. 200021-169679), ETH Research Grant (ETH-40 17-1), and Spanish MINECO (CTQ201568770-R). Dr. Sharon Mitchell and Dr. Frank Krumeich, Dr. Roland Hauert, Bharath Tata, and Prof. Gordana CirićMarjanović are kindly acknowledged for performing the microscopy, XPS, assistance with catalytic measurements, and the fruitful discussions, respectively. ScopeM at ETH Zurich is thanked for providing access to its facilities. E.F. thanks MINECO La Caixa-Severo Ochoa for a predoctoral grant through Severo Ochoa Excellence Accreditation 2014-2018 (SEV-2013-0319). BSC-RES is acknowledged for providing generous computational resources.

\section{Conflict of interest}

The authors declare no conflict of interest.

Keywords: alkyne semi-hydrogenation - gold .

molecular recognition $\mathrm{N}$-doped carbon - single-atom catalysis

[1] R. Dorel, A. M. Echavarren, Chem. Rev. 2015, 115, 9028-9072.

[2] a) M. Flytzani-Stephanopoulos, Acc. Chem. Res. 2014, 47, 783792; b) M. Yang, S. Li, Y. Wang, J. A. Herron, Y. Xu, L. F. Allard, S. Lee, J. Huang, M. Mavrikakis, M. Flytzani-Stephanopoulos, Science 2014, 346, 1498-1501; c) X. F. Yang, A. Q. Wang, B. T. Qiao, J. Li, J. Y. Liu, T. Zhang, Acc. Chem. Res. 2013, 46, $1740-$ 1748.

[3] a) Z. Chen, S. Pronkin, T.-P. Fellinger, K. Kailasam, G. Vilé, D. Albani, F. Krumeich, R. Leary, J. Barnard, J. M. Thomas, J. Pérez-Ramírez, M. Antonietti, D. Dontsova, ACS Nano 2016, $10,3166-3175$; b) N. Cheng, S. Stambula, D. Wang, M. N. Banis, J. Liu, A. Riese, B. Xiao, R. Li, T. K. Sham, L. M. Liu, G. A. Botton, X. Sun, Nat. Commun. 2016, 7, 13638; c) Y. J. Chen, S. F. Ji, Y. G. Wang, J. C. Dong, W. X. Chen, Z. Li, R. A. Shen, L. R. Zheng, Z. B. Zhuang, D. S. Wang, Y. D. Li, Angew. Chem. Int. Ed. 2017, 56, 6937-6941; Angew. Chem. 2017, 129, 7041-7045.

[4] a) G. Vilé, D. Albani, M. Nachtegaal, Z. Chen, D. Dontsova, M. Antonietti, N. López, J. Pérez-Ramírez, Angew. Chem. Int. Ed. 2015, 54, 11265-11269; Angew. Chem. 2015, 127, 11417-11422; b) D. A. Bulushev, M. Zacharska, E. V. Shlyakhova, A. L. Chuvilin, Y. N. Guo, S. Beloshapkin, A. V. Okotrub, L. G. Bulusheva, ACS Catal. 2016, 6, 681-691; c) P. Q. Yin, T. Yao, Y. Wu, L. R. Zheng, Y. Lin, W. Liu, H. X. Ju, J. F. Zhu, X. Hong, Z. X. Deng, G. Zhou, S. Q. Wei, Y. D. Li, Angew. Chem. Int. Ed. 2016, 55, 10800-10805; Angew. Chem. 2016, 128, 10958-10963.

[5] a) A. S. K. Hashmi, G. J. Hutchings, Angew. Chem. Int. Ed. 2006, 45, 7896-7936; Angew. Chem. 2006, 118, 8064-8105; b) A. M. Asiri, A. S. K. Hashmi, Chem. Soc. Rev. 2016, 45, 4471-4503.

[6] a) N. Masoud, L. Delannoy, H. Schaink, A. van der Eerden, J. W. de Rijk, T. A. G. Silva, D. Banerjee, J. D. Meeldijk, K. P. de Jong, C. Louis, P. E. de Jongh, ACS Catal. 2017, 7, 5594-5603; b) A. Hugon, L. Delannoy, C. Louis, Gold Bull. 2008, 41, 127-138.

[7] a) B. T. Qiao, J. X. Liu, Y. G. Wang, Q. Q. Lin, X. Y. Liu, A. Q. Wang, J. Li, T. Zhang, J. Y. Liu, ACS Catal. 2015, 5, 6249-6254; b) Z. Chen, Q. Zhang, W. X. Chen, J. C. Dong, H. R. Yao, X. B. Zhang, X. J. Tong, D. S. Wang, Q. Peng, C. Chen, W. He, Y. D. Li, Adv. Mater. 2018, 30, 8.

[8] G. Malta, S. A. Kondrat, J. S. Freakley, C. J. Davies, L. Lu, S. Dawson, A. Thetford, E. K. Gibson, D. J. Morgan, W. Jones, P. P. Wells, P. Johnston, C. R. A. Catlow, C. J. Kiely, G. J. Hutchings, Science 2017, 355, 1399-1403.

[9] a) M. García-Mota, N. Cabello, F. Maseras, A. M. Echavarren, J. Pérez-Ramírez, N. López, ChemPhysChem 2008, 9, 1624-1629; b) Y. Segura, N. López, J. Pérez-Ramírez, J. Catal. 2007, 247, $383-386$.

[10] R. Lin, S. K. Kaiser, R. Hauert, J. Pérez-Ramírez, ACS Catal. 2018, 8, 1114-1121.

[11] Y. Y. Fong, B. R. Visser, J. R. Gascooke, B. C. Cowie, L. Thomsen, G. F. Metha, M. A. Buntine, H. H. Harris, Langmuir 2011, 27, 8099-8104.

[12] F. W. Lytle, P. S. P. Wei, R. B. Greegor, G. H. Via, J. H. Sinfelt, J. Chem. Phys. 1979, 70, 4849-4855.

[13] a) C. Moreno-Marrodan, F. Liguori, P. Barbaro, Beilstein J. Org. Chem. 2017, 13, 734-754; b) J. A. Delgado, O. Benkirane, C. Claver, D. Curulla-Ferré, C. Godard, Dalton Trans. 2017, 46, 12381-12403; c) M. Eggersdorfer, D. Laudert, U. Létinois, T. 
McClymont, J. Medlock, T. Netscher, W. Bonrath, Angew. Chem. Int. Ed. 2012, 51, 12960-12990; Angew. Chem. 2012, 124, 13134 13165.

[14] J. L. Fiorio, N. López, L. M. Rossi, ACS Catal. 2017, 7, 2973 2980; J. L. Fiorio, R. V. Gonçalves, E. Teixeira-Neto, M. A. Ortuño, N. López, L. M. Rossi, ACS Catal. 2018, 8, 3516-3524.
[15] "Molecular Recognition": J. Lehn in Supramolecular Chemistry (Ed.: J. Lehn), Wiley, New York, 1995, https://doi.org/10.1002/ 3527607439.ch2.

Manuscript received: May 20, 2018

Accepted manuscript online: November 8, 2018

Version of record online: November 21, 2018 